\title{
MAKING DECISIONS ON ARRANGEMENT OF ELECTRONICS IN SMART GARMENT
}

\author{
Inese Parkova ${ }^{1}$, Andrejs Kašurins ${ }^{2}$, Aleksandrs Vališevskis ${ }^{1}$, \\ Ausma Viḷumsone ${ }^{1}$
}

1- Rigas Technical University, Institute of Textile Materials Technologies and Design

Azenes 14, Riga, LV 1048, Latvia; e-mail: inese.parkova@rtu.lv, aleksandrs.valisevskis@rtu.lv, ausma.vilumsone@rtu.lv

2- Rigas Technical University

Division of Mathematical Support of Transport Systems Control

Lomonosova 1/V, Riga, LV 1019, Latvia; e-mail: andrejs.kasurins@ rtu.lv

\begin{abstract}
This paper describes the prototype of a smart jacket and offers several alternative ways of designing and arranging of electronic elements, which are based on ergonomic design guidelines, using principles of external and internal stress zoning in garments. Seven variants of arrangement are proposed, which are compared using decision making methods AHP and ELECTRE. One of the goals of this research is to carefully aggregate the available information and to rank different variants of arrangement using a set of criteria as objectively as possible. Comparing several variants of arrangement of electronic elements in clothing enables one to determine the most suitable variants according to the selected criteria.
\end{abstract}

Keywords: smart garment, electronic system integration, clothing ergonomics, decision making.

\section{Introduction}

With wearable electronics usually denote a functioning device that always is attached to the wearer, as well as is comfortable, easy-care and easy-use. In other words - it is clothing with integrated electronics that does not disturb the wearer of the apparel. Therefore, during the development of the smart clothing it is important to consider design and arrangement of electronic elements in order to get functional, comfortable and ergonomic layout of electronic components in smart garment.

In this research we analyze construction of electronic part of a smart jacket prototype, searching ways of improvement and designing alternative variants of electronic element arrangement.

The aim of the research is to rank different variants of electronic element arrangement, to aggregate carefully the available information and to rank different variants of arrangement using a set of criteria as objectively as possible, using decision making method ELECTRE. AHP is used for criteria weighting. These methods are deemed necessary because the problem at hand is not a trivial one, since there are several possible alternatives, which are compared using a set of criteria of different importance. On the other hand, this approach is more feasible than the construction and testing of physical prototypes, which is too costly in terms of time and resources.

\section{Materials and methods}

This chapter provides description of the prototype, of different ways to improve its construction and offers several alternative construction variants. Used decision making methods are described and the decision problem is analysed. 


\section{Description of prototype}

The developed prototype is an innovative solution in the field of child care and safety; it is a garment, which reacts to microclimate changes with the help of integrated electronics and signals temperature and relative humidity.

Output interface is represented in two ways:

1) with the help of optical fibre fabric integrated into clothing: when microclimate conditions change, fabric starts to emit light with a different frequency;

2) with the help of a LCD screen integrated into mother's purse and displaying information about the child's body temperature and relative humidity. Maximum operational range between the purse and the jacket is about $30 \mathrm{~m}$, ZigBee is used for wireless communication.

In addition to its decorative and functional properties, this light-emitting children's garment will protect children on dark roads and will help parents to take better care of their children.

\section{Arrangement of electronic elements in the prototype}

Electronic elements are integrated in a way that makes it possible to remove them before washing. For this purpose, a removable layer for electronic components was developed. Light emitting diode and mode button are permanently integrated into clothing and are not removable, all the other electronic elements are placed on a removable layer, which is placed in the back of the jacket and is attached to the jacket with the help of 6 press studs. Jacket construction and electronics layout is shown in Fig.1. Information on prototype functionality and a broader description was published in one of the previous papers [1].

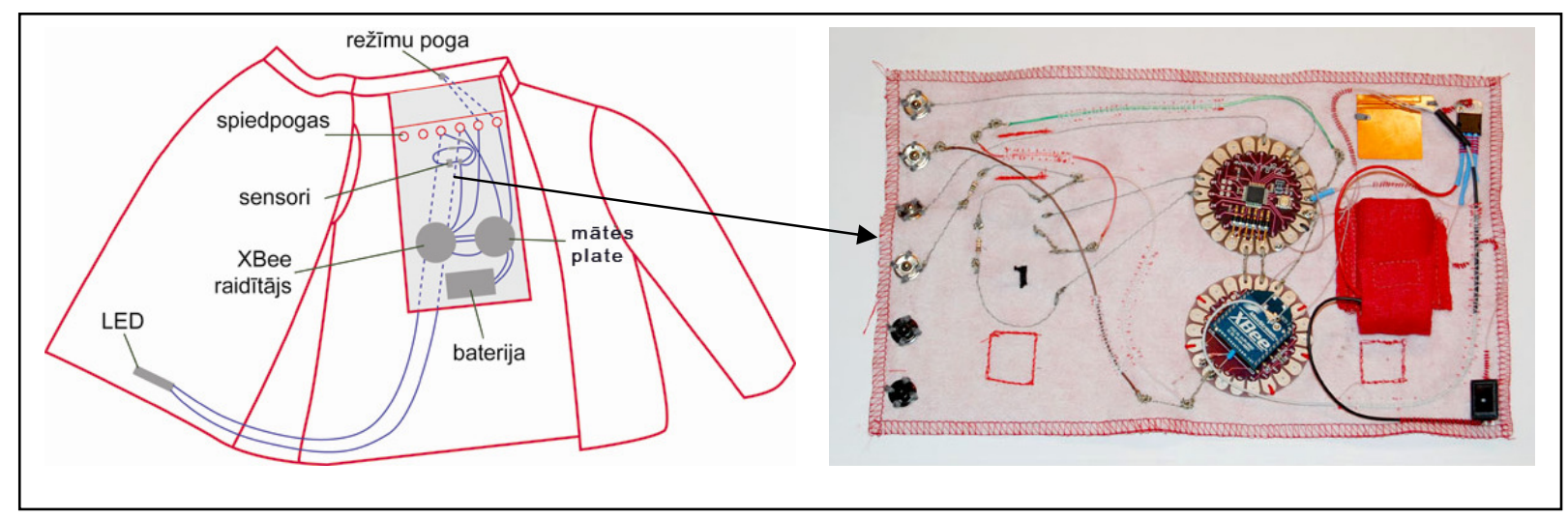

Fig.1. Jacket construction and electronics layout

One of the disadvantages of this system is a possible risk of injury if a child falls on its back, since battery and RF-transmitter are located there - these modules are larger than other elements and they are located in the backbone area. In order to solve this problem, it is possible to attach additional isolation layer to the area in question. Another solution would be to provide an alternative arrangement of electronic elements in the jacket.

\section{Improving the layout of electronic elements}

One of goals during the optimization of jacket construction was to ensure that the garment follows ergonomic design guidelines. For the integration of electronic modules into wearable garments it is important to take into consideration arrangement, weight distribution and selection of suitable clothing area. Principles of external and internal stress zoning in garments (Standard EN 13595-1: 2002 Protective clothing for professional motorcycle riders: zoning of risk categories; and Ashdown and Watkins research about identification of stresses on seams during wear) were analyzed and the results can be found in one of the previous papers [2]. According to external and internal zoning principles it can be derived that the most 
suitable zones for electronic elements are jacket front side and back side till waist level, as well as small zone on sleeve between shoulder and elbow. Of course we have to take into account that clothing is tailored to child and there can be certain deviation from fixed zones in clothing.

Besides principles of zoning other ergonomic requirements have been proposed:

- It is necessary to ensure equal weight and size distribution of electronic elements in clothing.

- Electronic elements must be placed in such a way that children cannot reach and damage them.

- Electronic elements must be chosen as small as possible both in weight and size.

Analysis of the requirements mentioned above and optimization of jacket design resulted in several alternative proposals of electronic elements distribution in child jacket. These variants are described in Table 1.

Table 1.

Alternative variants for arrangement of electronic elements in child jacket

\begin{tabular}{|c|c|c|c|}
\hline Var & Title & Description & $\begin{array}{c}\text { Advantages and } \\
\text { drawbacks }\end{array}$ \\
\hline 1 & 2 & 3 & 4 \\
\hline A & $\begin{array}{l}\text { Removable layer } \\
\text { in back part and } \\
\text { inner pockets for } \\
\text { electronic } \\
\text { elements }\end{array}$ & $\begin{array}{l}\text { The same electronic as in the original } \\
\text { prototype are used. LED and mode button } \\
\text { are permanently integrated into the jacket. } \\
\text { Part of electronic elements are located on } \\
\text { the removable layer in the back, other } \\
\text { elements are positioned laterally above } \\
\text { waist level in pockets under lining. Bulky } \\
\text { elements are placed in pockets, so that } \\
\text { they don't cause discomfort to the wearer } \\
\text { with stress in backside. Balanced weight } \\
\text { distribution is obtained. }\end{array}$ & $\begin{array}{l}\text { Circuit advantages: } \\
\text { Balanced weight } \\
\text { distribution, easy battery } \\
\text { change. } \\
\text { Circuit drawbacks: High } \\
\text { costs, large dimensions of } \\
\text { electronic elements, } \\
\text { complicated removal of } \\
\text { electronic block before } \\
\text { washing. }\end{array}$ \\
\hline B & $\begin{array}{l}\text { Removable layer } \\
\text { in back part and } \\
\text { outer pocket for } \\
\text { electronic } \\
\text { elements }\end{array}$ & $\begin{array}{l}\text { Alternative electronic elements are used - } \\
\text { smaller in size and weight. The most } \\
\text { problematic element still is a bulky } \\
\text { battery (9V PP3). Electronic elements are } \\
\text { located on removable layer in the back, } \\
\text { which is more compact due to the } \\
\text { dimensions of the elements - the layer is } \\
\text { more compact. Battery and switch are } \\
\text { located in the outer pocket on the jacket's } \\
\text { sleeve. }\end{array}$ & $\begin{array}{l}\text { Circuit advantages: Lower } \\
\text { costs, minimized } \\
\text { dimensions of elements, } \\
\text { easy battery change. } \\
\text { Circuit drawbacks: Quite } \\
\text { complicated removal of } \\
\text { electronics before } \\
\text { washing. }\end{array}$ \\
\hline $\mathrm{C}$ & $\begin{array}{l}\text { Lateral } \\
\text { removable layer } \\
\text { and outer } \\
\text { pockets for } \\
\text { electronic } \\
\text { elements }\end{array}$ & $\begin{array}{l}\text { This variant is similar to the one } \\
\text { mentioned above - electronic elements are } \\
\text { located on the lateral removable layer, } \\
\text { battery and switch are located in outer } \\
\text { pocket on the jacket's sleeve. Lateral } \\
\text { arrangement of the layer ensures better } \\
\text { microclimate data readout and gives } \\
\text { additional protection by wearer's hand. }\end{array}$ & $\begin{array}{l}\text { Circuit advantages: Better } \\
\text { microclimate data readout; } \\
\text { extra scheme protection. } \\
\text { Circuit drawbacks: Longer } \\
\text { contact paths, lateral } \\
\text { attrition. }\end{array}$ \\
\hline
\end{tabular}


Parkova I., Kašurins A., Vališevskis A.,

\begin{tabular}{|c|c|c|c|}
\hline 1 & 2 & 3 & 4 \\
\hline $\mathrm{D}$ & $\begin{array}{l}\text { Removable layer } \\
\text { in front part for } \\
\text { arrangement of } \\
\text { electronic } \\
\text { elements }\end{array}$ & $\begin{array}{l}\text { According to external and internal zoning } \\
\text { principles, safer placement zone for } \\
\text { electronic elements is front of the jacket, } \\
\text { thus electronic elements arrangement in } \\
\text { the front part of the jacket below optical } \\
\text { fiber fabric is provided. } \\
\text { LED and mode button are permanently } \\
\text { integrated into the clothing, all other } \\
\text { electronic elements are located on the } \\
\text { removable layer in the front part of jacket. }\end{array}$ & $\begin{array}{l}\text { Circuit advantages: Lower } \\
\text { costs, compact disposition, } \\
\text { easy removal of electronic } \\
\text { block. } \\
\text { Circuit drawbacks: Worse } \\
\text { microclimate data readout } \\
\text { due to position of sensors, } \\
\text { battery change is not very } \\
\text { handy. }\end{array}$ \\
\hline $\mathrm{E}$ & $\begin{array}{l}\text { Removable layer } \\
\text { in front part and } \\
\text { inner pockets for } \\
\text { power supply }\end{array}$ & $\begin{array}{l}\text { Similar to the variant mentioned above, } \\
\text { but in this case there is a better weight } \\
\text { distribution, because the batteries are } \\
\text { moved from the removable layer to inner } \\
\text { pockets positioned laterally above waist } \\
\text { level under lining and they are placed } \\
\text { symmetrically - one at each side. Two } \\
\text { AA batteries are used in this variant. }\end{array}$ & $\begin{array}{l}\text { Circuit advantages: Lower } \\
\text { costs, zoning principle, } \\
\text { balanced weight } \\
\text { distribution. } \\
\text { Circuit drawbacks: Quite } \\
\text { complicated removal of } \\
\text { electronic block before } \\
\text { washing. }\end{array}$ \\
\hline $\mathrm{F}$ & $\begin{array}{l}\text { Removable layer } \\
\text { in back part and } \\
\text { inner pockets for } \\
\text { power supply }\end{array}$ & $\begin{array}{l}\text { Such symmetrical battery arrangement is } \\
\text { preferable to use if electronic elements are } \\
\text { located on removable layer on the back. } \\
\text { Two AA batteries are used in this variant. }\end{array}$ & $\begin{array}{l}\text { Circuit advantages: Lower } \\
\text { costs, zoning principle, } \\
\text { balanced weight } \\
\text { distribution. } \\
\text { Circuit drawbacks: Quite } \\
\text { complicated removal of } \\
\text { electronic block before } \\
\text { washing. }\end{array}$ \\
\hline
\end{tabular}

Schemes of alternative variants of electronic elements arrangement and design in child jacket are shown in Fig.2.

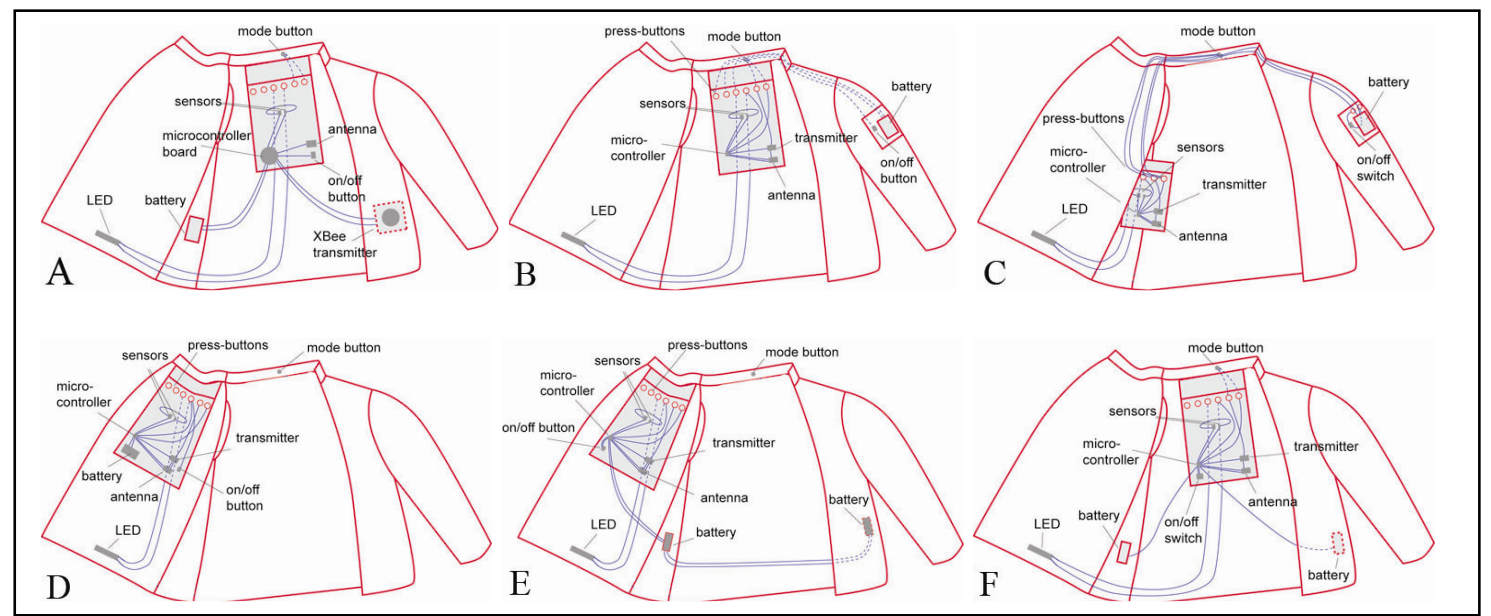

Fig.2. Schemes of alternative variants of electronic elements arrangement and design in child jacket 


\section{Decision making methods for objective analysis of subjective data}

Decision making is the study of identifying and choosing alternatives based on the values and preferences of the decision maker. Making a decision implies that there are alternative choices to be considered, and in such a case we want not only to identify as many of these alternatives as possible but to choose the one that best fits with our goals, objectives, desires, values, and so on. To perform the multi-criteria analysis, we consider two proven techniques. The first one is ELECTRE, which aims at establishing an outranking relationship among alternatives. The second method is AHP, which is based on pairwise comparisons of criteria. The rationale behind choosing these methods was the fact that they are human-centered and enable one to model and formalize decision maker's subjective preference in a seamless and intuitive way.

\section{- ELECTRE method description}

The ELECTRE methodology is based on the concordance and discordance indices defined as follows. We start from the data of the decision matrix, and assume that the sum of the weights of all criteria equals to 1 . For an ordered pair of alternatives $\left(\mathbf{A}_{j}, \mathbf{A}_{k}\right)$, the concordance index $c_{j k}$ is the sum of all the weights for those criteria where the performance score of $\mathbf{A}_{j}$ is least as high as that of $\mathbf{A}_{k}$, i.e.

$$
c_{j k} \sum_{i: a_{i j} \geq a_{i k}} w_{i}, \quad j, k=1, \ldots, n, \quad j \neq k .
$$

Clearly, the concordance index lies between 0 and 1 .

The computation of the discordance index $d_{j k}$ is a bit more complicated: $d_{j k}=0$ if $a_{i j}>a_{i k}$, $i=1, \ldots, m$, i.e. the discordance index is zero if $\mathbf{A}_{j}$ performs better than $\mathbf{A}_{k}$ on all criteria,. Otherwise,

$$
d_{j k}=\max _{i=1, \ldots, m} \frac{a_{i k}-a_{i j}}{\max _{j=1, \ldots, n} a_{i k}-\min _{j=1, \ldots, n} a_{i j}}, \quad j, k=1, \ldots, n, \quad j \neq k
$$

i.e. for each criterion where $\mathbf{A}_{k}$ outperforms $\mathbf{A}_{j}$, the ratio is calculated between the difference in performance level between $\mathbf{A}_{k}$ and $\mathbf{A}_{j}$ and the maximum difference in score on the criterion concerned between any pair of alternatives. The maximum of these ratios (which must lie between 0 and 1 ) is the discordance index.

A concordance threshold $c^{*}$ and discordance threshold $d^{*}$ are then defined such that $0<d^{*}<\mathrm{c}^{*}<1$.

Then, $\mathbf{A}_{j}$ outranks $\mathbf{A}_{k}$ if the $c_{j k}>c^{*}$ and $d_{j k}<d^{*}$, i.e. the concordance index is above and the discordance index is below its threshold, respectively.

This outranking defines a partial ranking on the set of alternatives. Consider the set of all alternatives that outrank at least one other alternative and are themselves not outranked. This set contains the promising alternatives for this decision problem. Interactively changing the level thresholds, we also can change the size of this set.

The ELECTRE I method is used to construct a partial ranking and choose a set of promising alternatives.

\section{- Analytic Hierarchy Process (AHP) method description}

The basic idea of the AHP approach is to convert subjective assessments of relative importance to a set of overall scores or weights [3]. AHP is a quantitative comparison method used to select a preferred alternative by using pair-wise comparisons of the alternatives based on their relative performance against the criteria [4]. For each pair of criteria, the decision maker is required to respond to a pairwise comparison question asking the relative importance 
of the two. The responses can use the following nine-point scale expressing the intensity of the preference for one criterion versus another:

$1=$ Equal importance or preference.

$3=$ Moderate importance or preference of one over another.

$5=$ Strong or essential importance or preference.

$7=$ Very strong or demonstrated importance or preference.

$9=$ Extreme importance or preference.

If the judgement is that criterion $\mathbf{C} j$ is more important than criterion $\mathbf{C} i$, then the reciprocal of the relevant index value is assigned [3].

\section{Description and analysis of criteria for electronic elements arrangement}

One of the goals of this research is to carefully define a set of criteria that would make it possible to compare variants of arrangement as objectively as possible.

Criteria should be [3]:

- able to discriminate among the alternatives and to support the comparison of the

performance of the alternatives,

- complete to include all goals,

- operational and meaningful,

- non-redundant,

- few in number.

Eight criteria were used for analysis and they are described below.

1. Dimension of electronics. It is preferable to use electronic elements, which are as small as possible in weight and size to ensure that the smart garment is comfortable to wear.

2. Electronic block removal. Since integration of electronic was provided in a way that makes it possible to remove it before garment washing, it is important to ensure easy electronic block removal. Attachment technology, number of disjoining cycles at one time etc. are considered.

3. Battery change. The power for this item is supplied from battery, so it is necessary to provide easy battery replacement - battery must be easy to find, to disconnect and to connect.

4. Cost. Costs of electronic elements were taken into consideration.

5. Microclimate data readout. It is preferable to place sensors in area where sweating is intensive, so that the sensors are able to react to the microclimate changes as fast and as precise as possible.

6. Weight distribution. Relatively proportional weight distribution is important - it is relevant from ergonomic aspect, as well as it prevents clothing from being skewed to one side.

7. Inaccessibility of electronic components by child. Since jacket is intended for a child, it is important that the child cannot access electronic block - to damage it or to injure himself by choking small elements.

8. Zoning. According to the analyzed principles of external and internal zoning it follows that the most suitable zones for electronic elements are front and back side of jacket till waist level, as well as small area on sleeve between shoulder and elbow.

Weight coefficients of criteria were estimated using AHP method, by indicating how important criterion $\mathbf{C} i$ is relative to criterion $\mathbf{C} j$. Pairwise comparison matrix is shown in Table 2. 
Table 2.

Pairwise Comparison Matrix

\begin{tabular}{|c|c|c|c|c|c|c|c|c|}
\hline Crit.N. & $\mathbf{1}$ & $\mathbf{2}$ & $\mathbf{3}$ & $\mathbf{4}$ & $\mathbf{5}$ & $\mathbf{6}$ & $\mathbf{7}$ & $\boldsymbol{8}$ \\
\hline $\boldsymbol{1}$ & 1 & 1.5 & 1.5 & 3 & 1.5 & 2.5 & 3 & 2.5 \\
\hline $\mathbf{2}$ & 0.67 & 1 & 0.67 & 2.5 & 1 & 2.5 & 3 & 2.5 \\
\hline $\mathbf{3}$ & 0.67 & 1.5 & 1 & 2 & 1 & 2.5 & 3 & 2.5 \\
\hline $\mathbf{4}$ & 0.33 & 0.4 & 0.5 & 1 & 0.5 & 0.5 & 0.5 & 1 \\
\hline $\mathbf{5}$ & 0.67 & 1 & 1 & 2 & 1 & 2 & 2 & 2 \\
\hline $\mathbf{6}$ & 0.4 & 0.4 & 0.4 & 2 & 0.5 & 1 & 1 & 2 \\
\hline $\mathbf{7}$ & 0.33 & 0.33 & 0.33 & 2 & 0.5 & 1 & 1 & 1 \\
\hline $\boldsymbol{8}$ & 0.4 & 0.4 & 0.4 & 1 & 0.5 & 0.5 & 1 & 1 \\
\hline
\end{tabular}

\section{Comparison of electronic elements arrangement variants}

The original prototype $(\mathrm{P})$ and alternative improved designs (A, B, C, D, E, F) were considered in the analysis. Each variant was evaluated according to each criterion, evaluating it using a ten-point scale, where 1 was the lowest estimation and 10 was the highest estimation. Performance of alternatives on criteria was evaluated in relation to other analyzed alternatives, thus these evaluations are not universal and apply only to the problem considered. Estimations for alternatives and calculated weight coefficients are shown in Table 3.

Table 3.

Comparison of electronic elements arrangement variants

\begin{tabular}{|l|l|c|c|c|c|c|c|c|c|}
\hline \multirow{2}{*}{ No. Criteria } & \multicolumn{7}{|c|}{ Estimations for alternatives } & \multirow{2}{*}{ Weight } \\
\cline { 3 - 10 } & & P & A & B & C & D & E & F & \\
\hline 1 & Dimension of electronics & 4 & 4 & 10 & 10 & 10 & 10 & 10 & 0.21 \\
\hline 2 & Electronic block removal & 10 & 7 & 9 & 9 & 10 & 7 & 7 & 0.16 \\
\hline 3 & Battery change & 8 & 9 & 10 & 10 & 8 & 7 & 7 & 0.18 \\
\hline 4 & Cost & 5 & 5 & 10 & 10 & 10 & 10 & 10 & 0.06 \\
\hline 5 & Microclimate data readout & 9 & 9 & 9 & 10 & 7 & 7 & 9 & 0.15 \\
\hline 6 & Inaccessibility for child & 10 & 10 & 10 & 7 & 7 & 7 & 10 & 0.09 \\
\hline 7 & Weight distribution & 8 & 10 & 9 & 9 & 8 & 10 & 10 & 0.08 \\
\hline 8 & Zoning & 4 & 8 & 8 & 9 & 10 & 10 & 8 & 0.07 \\
\hline
\end{tabular}

\section{Results}

Concordance indices matrix of object dominance and discordance indices matrix of object dominance is calculated and the results are shown in Table 4. These indices are in interval $0 \ldots 1$ and define concordance and discordance with hypothesis that alternative A dominates alternative $\mathrm{B}$.

Table 4.

\section{Concordance and discordance indices matrix}

\begin{tabular}{|c|c|c|c|c|c|c|c|c|c|c|c|c|c|c|c|}
\hline \multicolumn{8}{|c|}{ Concordance matrix } & \multicolumn{7}{|c|}{ Discordance matrix } \\
\hline & P & A & B & C & D & E & F & & P & A & B & C & D & E & F \\
\hline P & - & 0.12 & 0.12 & 0.25 & 0.25 & 0.5 & 0.25 & P & - & 0.11 & 0.6 & 0.6 & 0.6 & 0.6 & 0.6 \\
\hline A & 0.38 & - & 0.12 & 0.25 & 0.5 & 0.38 & 0.12 & A & 0 & - & 0.6 & 0.6 & 0.6 & 0.6 & 0.6 \\
\hline B & 0.62 & 0.5 & - & 0.12 & 0.5 & 0.5 & 0.25 & B & 0 & 0 & - & 0 & 0.1 & 0 & 0 \\
\hline C & 0.75 & 0.75 & 0.25 & - & 0.38 & 0.38 & 0.5 & C & 0 & 0 & 0 & - & 0.1 & 0 & 0.3 \\
\hline D & 0.38 & 0.5 & 0.25 & 0.25 & - & 0.25 & 0.38 & D & 0 & 0 & 0 & 0 & - & 0 & 0.3 \\
\hline E & 0.5 & 0.38 & 0.25 & 0.25 & 0.12 & - & 0.12 & E & 0 & 0 & 0 & 0 & 0 & - & 0 \\
\hline F & 0.5 & 0.25 & 0.12 & 0.25 & 0.38 & 0.25 & - & F & 0 & 0 & 0 & 0 & 0 & 0 & - \\
\hline
\end{tabular}


The limiting values used in outranking relation are chosen to be $\mathrm{c}^{*}=0.45$ and $\mathrm{d}^{*}=0.4$. Partial ranking on the set of alternatives is shown in Fig.3.

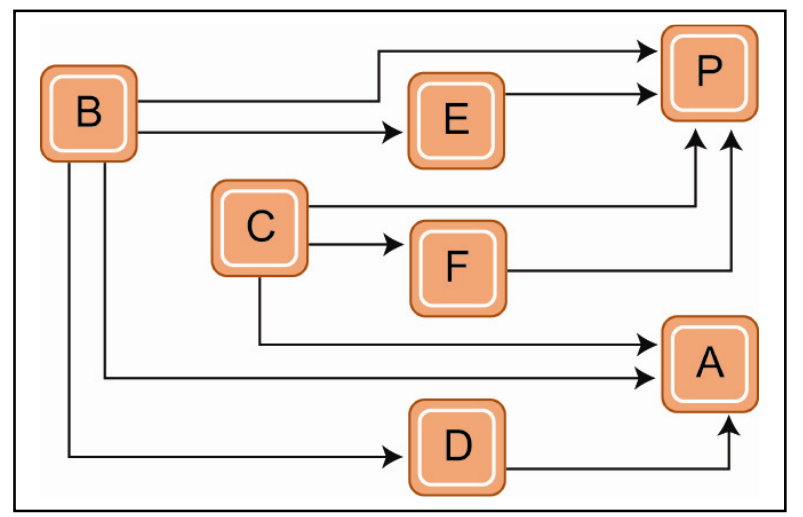

Fig.3. Partial ranking on the set of alternatives

In the diagram of partial ranking on the set of alternatives we can see that the most suitable variants for electronic elements arrangement in clothing are alternatives $\mathrm{B}$ and $\mathrm{C}$, which are not dominated.

\section{Concluding discussion}

Comparison of several variants of arrangement of electronic elements in clothing based on decision making methods AHP and ELECTRE shows that the most suitable variants according to the selected criteria and evaluation of alternatives are variant $\mathrm{B}$ with removable layer in the back part and outer pocket for electronic elements and variant $\mathrm{C}$ with removable layer in the lateral part and outer pockets for electronic elements.

One of the goals of this research was to carefully choose a set of criteria what would make it possible to compare different variants of arrangement as objectively as possible. Such set is presented and description for each criterion is provided. The decision methods used, which are based on criteria selection and evaluation of alternatives, help to choose the most suitable arrangement of electronic components in smart clothing. This method is especially useful when large number of alternatives and criteria have to be analyzed.

This paper describes a study on designing of electronic part in a smart child jacket, which reacts to microclimate changes with the help of integrated electronics and signals about temperature and relative humidity inside the jacket. The paper describes arrangement of electronic components in jacket, as well as different ways of improving this arrangement by providing several alternative variants. Seven variants of arrangement are described, which are compared using decision making methods. To perform the multi-criteria analysis, two proven techniques were considered - AHP and ELECTRE. Comparison of several variants of arrangement of electronic elements in clothing shows the most suitable variants corresponding to the selected criteria.

\section{Acknowledgment}

This work has been supported by the European Social Fund within the projects "Support for the implementation of doctoral studies at Riga Technical University" and "Establishment of interdisciplinary research groups for new functional properties of smart textiles development and integrating in innovative products". 
Parkova I., Kašurins A., Vališevskis A.,

Viḷumsone A. MAKING DECISIONS ON ARRANGEMENT OF ELECTRONICS IN SMART GARMENT

\section{References}

1. Parkova I., Valishevskis A., Ziemele I., Vil̦umsone A. Integration of optical fibers into textile products. 9th International Conference on Global Research and Education Inter-Academia 2010, Riga (in English)

2. Parkova I., Valishevskis A., Ziemele I., Viļumsone A. Disposition of electronic systems into clothing. RTU 51. International scientific conference 2010, Riga (in Latvian)

3. Figueira, J., Mousseau, V., andRoy, B., "ELECTRE methods", In: Figueira, J., Greco, S., and Ehrgott, M., (Eds.), Multiple Criteria Decision Analysis: State of the Art Surveys, Springer, New York, 2005, pp 133-162 (in English)

4. Baker D., Bridges D., Hunter R., Johnson G., Krupa J., Murphy J., Sorenson K. Guidebook to decisionmaking methods. 2001, pp 7 (in English) 